\title{
Reflexões sobre edições digitais: fazendo filologia no século XXI
}

\author{
Reflections about digital editions: making philology in the 21st century \\ Lívia Borges Souza Magalhães* \\ Universidade Federal da Babia, Salvador, Bahia, Brasil \\ Alícia Duhá Lose** \\ Universidade Federal da Bahia, Salvador, Bahia, Brasil
}

\begin{abstract}
Resumo: Como um reflexo da Terceira Revolução Industrial, o mundo começou a vivenciar um crescimento significativo de novas tecnologias de informação e comunicação, ocasionando uma mudança de paradigma social caracterizada pela ampla valorização da informação. Tal mudança trouxe possibilidades de modificações para as instituições e ciências, sem que elas percam as bases que as caracterizam. e, nesse âmbito, encontra-se a filologia que passou a ter no seu rol de práticas a construção de edições digitais. Assim, o trabalho aqui apresentado é uma proposta de definição e caracterização das edições, com exemplificações de trabalhos realizados por dois grupos de pesquisas filológicas da Bahia.
\end{abstract}

Palavras chave: Filologia. Edição Digital. Bahia

\begin{abstract}
As a reflection of the Third Industrial Revolution, the world began to experience a significant growth of new information and communication technologies, causing a social paradigm shift characterized by the widespread appreciation of information. Such a change has brought possibilities for changes to institutions and sciences, without losing the bases that characterize them. And, in this place, is the philology that began to have in its role of practices the construction of digital editions. Thus, the work presented here is a proposal for the definition and characterization of editions, with examples of works carried out by two philological research groups in Bahia.
\end{abstract}

Keywords: Philology. Digital Edition. Bahia

\section{INTRODUÇÃO}

Tarefas cotidianas como, por exemplo, fazer compras, agora são constantemente realizadas através de aparelhos conectados a uma rede mundial de computadores, apresentando uma nova configuração de sociedade que, paulatinamente, torna-se cada vez mais usuária e dependente de internet, firmando uma das características da terceira revolução industrial que, como aponta Jeremy Rifkin (2014), trouxe modificações no âmbito social, econômico e cultural, atingindo, consequentemente, as ciências, posto que elas precisam transformar-se em um universo de relações, seguindo a demanda do mundo.

A filologia, enquanto ciência extremamente atuante no século XXI, passa por esse processo de transformação em função da evolução tecnológica, não modificando sua metodologia, mas sim as práticas de execução. Agora, por exemplo, não mais se trabalha com lupas no processo de transcrição, faz-se uma foto de alta resolução e utiliza-se o zoom dos editores de imagem para captar todas as nuances do documento em estudo. Pode-se observar, também, a possibilidade de editar colocando os elementos paratextuais, graças ao recurso do hiperlink, dentro do texto, configurando o que Lose (2011) chamou de edição digital

A edição digital, e não edição meramente em formato digital, mostra-se um tipo completamente adequado à Filologia que precisa não somente trabalhar o texto, mas também o paratexto, as informações que contextualizam e dão sentido ao documento editado. Nas edições anteriores

\footnotetext{
*Doutoranda em Língua e Cultura pela Universidade Federal da Bahia. Email: maglivia@gmail.com.

** Doutora, professora do Departamento de Fundamentos para o Estudo das Letras da Universidade Federal da Bahia. Salvador, Bahia, Brasil. E-mail: alicialose@gmail.com.
} 
tais informações vinham como arredores, mas na edição digital esse arcabouço informacional está totalmente integrado ao texto transcrito, criando assim uma sintonia perfeita entre a transcrição e todas as informações que foram necessárias para que o filólogo adentrasse esse texto, e, consequentemente, desempenhasse sua função (de trazer o texto fidedigno) com mais confiança e clareza. O entorno do texto é sempre fundamental para uma boa edição e a edição digital possibilita esse diálogo de forma natural e soberana. A edição digital mostra-se completa, pois o editor pode escolher os critérios de qualquer tipo de transcrição já existente e fazer dialogar isso através de hiperlinks com seu paratexto, além de desdobramento de abreviaturas, movimentos de correção do autor, em caso de texto moderno, entre outras possibilidades. Além disso, tornar o texto digital é possibilitar sua divulgação de forma mais fácil, acessível e abrangente. O que se sente é que a Filologia estava à espera desse tipo de edição para conseguir fazer promover este diálogo entre as suas muitas faces, as suas tantas atividades, de forma democrática e interativa (LOSE et al., 2011, p. 78).

É a disposição, então, que deve ser considerada como a grande inovação dessas edições: não são dois textos dialogando, são camadas de texto, é, por assim dizer, um texto só, carregado de complementos a que o leitor terá acesso se quiser receber essa complementariedade. É neste quesito que se tem uma quebra da linearidade textual o que, como aponta Chartier (2009, p. 88), permite novos "[...] usos, manuseios e intervenções por parte dos leitores que são infinitamente mais numerosos e mais livres".

\section{DEFININDO E CARACTERIZANDO, POR ORA, AS EDIÇÕES DIGITAIS}

Alguns autores como, por exemplo, Ribeiro (2005) lembram que a ausência da linearidade de leitura aparece nos mais diversos textos, inclusive os mais antigos, graças à utilização de recursos como a nota de rodapé ou os glossários. A autora sinaliza então:

Com o advento de novas tecnologias de suporte para escrita e leitura, o hipertexto passou a ser usado como sinônimo de texto não-linear em meio digital, dando a (falsa) impressão de que é uma novidade relacionada, necessariamente, à Rede Mundial de Computadores. Não é o que mostra, no entanto, a história das práticas de leitura, assim como a dos suportes, da produção editorial e das tecnologias de gestão de conhecimento.

Contudo, a noção de linearidade precisa ser ampliada para abarcar a realidade texto digital. As práticas de leitura são, genuinamente, lineares, mas, eventualmente, o autor coloca uma indicação de nota de rodapé ou um cabedal, fazendo o leitor pausar a leitura em execução e iniciar a do que foi sinalizado como elemento importante de se ler antes de dar sequência ao texto. Tem-se, então, uma leitura não-linear referenciada pelos autores. Entretanto, essa não linearidade é estática, o leitor só tem duas opções: ou segue a leitura desprezando a nota de rodapé ou para a leitura, capta a informação de fora da leitura e retoma a linearidade.

A não-linearidade do texto digital é significativamente mais ampla, pois é dinâmica, visto que se disponibilizam diversos caminhos de leitura. Ela pode configurar-se de duas maneiras: a primeira delas, e mais comumente usada nas produções filológicas até o momento, é uma não-linearidade dinâmica fechada, na qual o editor não utiliza a rede mundial de computadores para a construção, mas constrói um arquivo em HyperText Markup Language (HTML) e insere diversos links no texto (construindo hipertextos) que direcionam o leitor para os elementos de complementariedade da edição. É o caso, por exemplo, da edição digital construída por Lose em 2004, pois os links foram usados para demonstrar os movimentos de escrita realizados por Arthur de Salles na produção de suas obras e para ligar as transcrições aos seus respectivos fac-símiles e descrições paleográficas, ou seja, são, como aponta Leão (1999), links disjuntivos, capazes de levar o leitor de uma parte a outra do mesmo sistema. Assim, embora ela tenha sido elaborada numa base que 
permite a sua publicação on-line a qualquer momento, ela coloca em diálogo apenas elementos internos da própria edição, fazendo com que a ligação com a rede seja desnecessária.

Concomitantemente existe a não-linearidade dinâmica aberta, caracterizada pelo uso dos links tanto para a construção de hipertextos como para o direcionamento do leitor para elementos na rede mundial de computadores e, consequentemente, para uma gama gigantesca de informações. Um exemplo de edição deste tipo é a edição digital do Livro de Crônicas do Mosteiro de São Bento da Bahia (MAGALHÃES, 2013) que, além dos elementos hipertextuais, apresenta links como, por exemplo, os que direcionam o leitor para informações complementares sobre fatos históricos citados no manuscrito em estudo remetendo a páginas já existentes na web, os chamados links conjuntivos.

As principais características da não-linearidade dinâmica aberta são: o fato dela precisar estar on-line para funcionar plenamente. Exemplifica-se mais uma vez: o leitor toma a edição digital do Livro de Crônicas do Mosteiro de São Bento da Bahia (MAGALHÃES, 2013) e se depara com o link "leia mais", fazendo um convite para que ele acesse a mais informações, nesse caso, sobre o convento das Mercês. Ao clicar no link, há um direcionamento para uma página pré-existente na web que conta a história do convento. Essa página apresenta imagens da região e outros links que vão contar mais informações sobre a localidade, abas com indicação de leitura e vídeos começam a surgir na tela e, assim, o leitor tem a opção de abandonar a edição filológica temporariamente e seguir seus caminhos, construindo o seu conhecimento ao seu modo.

Figura 1: Edição digital do Livro de Crônicas com indicações de "leia mais"

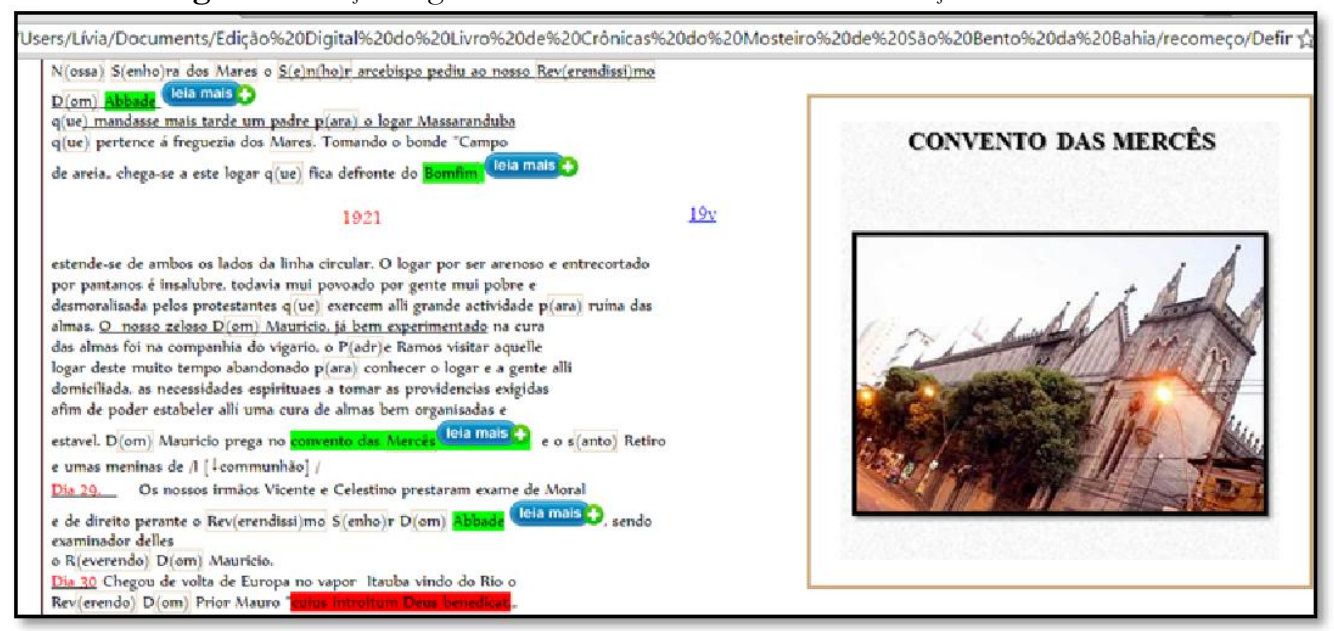

Fonte: MAGALHÃES, 2013.

A não-linearidade dinâmica é, na realidade, uma definição da Física que serve de base para a teoria do caos, uma teoria que se aplica a existência de quase tudo do universo, sendo aqui utilizada em prol da filologia. Vale destacar, no entanto, que ao contrário do que se propaga na sociedade, o caos não é sinônimo de desordem, mas sim de imprevisibilidade

\footnotetext{
Em contraposição à ideia de ausência de ordem que intuímos, a Teoria do Caos está justamente ligada à descoberta de padrões e leis razoavelmente simples governando uma série de fenômenos complexos. Mas não se confunda esta existência de padrões com a possibilidade de previsão. Uma característica dos sistemas caóticos é que qualquer mínima alteração em uma das suas condições iniciais pode provocar profundas mudanças de trajetória ou comportamento. Daí a imprevisibilidade. (WOOD JR, 1111993, p. 95)
}

Uma leitura imprevisível é, sem dúvida, uma ótimo descrição da maneira como se lê no ambiente virtual e, consequentemente, as edições digitais, pois tal leitura permite aos sujeitos o processamento e a troca e, além disso, "os canais de distribuição são ágeis, não 
dependem de cadeias de distribuição ou limitações espaciais ou geográficas, alterando a informação no contexto social em diferentes escalas, de acordo com a natureza constituída na documentação circulante." (SERRA, 2014, p. 77)

Assim, apresenta-se, por ora, termos usados para definir e caracterizar essas edições filológicas em HTML, relembrando, contudo, que eles são noções de uma prática ainda em consolidação e, por isso, não configuram-se como um conceito estabelecido, mas uma proposta focando em aspectos notórios: os dígitos binários e, paralelamente, adicionar adjetivos que auxiliem na diferenciação da edição em questão.

\section{A PRODUÇÃO DE EDIÇÕES DIGITAIS NA BAHIA}

As produções de edições digitais são tão antigas quanto o computador. Esse tipo de trabalho nasce com o Padre Roberto Busa, um jesuíta italiano, nascido no começo século XX e considerado o pai das Humanidades Digitais, pois foi o primeiro a utilizar máquinas capazes de processar dígitos em prol do conhecimento das ciências humanas.

O trabalho dele consistia em:

A purely mechanical concordance program, where words are alphabetized according to their graphic forms (sequences of letters), could have produced a result in much less time, but Busa would not be satisfied with this. He wanted to produce a "lemmatized" concordance where words are listed under their dictionary headings, not under their simple forms. His team attempted to write some computer software to deal with this and, eventually, the lemmatization of all 11 million words was completed in a semiautomatic way with human beings dealing with word forms that the program could not handle. Busa set very high standards for his work. His volumes are elegantly typeset and he would not compromise on any levels of scholarship in order to get the work done faster. He has continued to have a profound influence on humanities computing, with a vision and imagination that reach beyond the horizons of many of the current generation of practitioners who have been brought up with the Internet. A CD-ROM of the Aquinas material appeared in 1992 that incorporated some hypertextual features ("cum hypertextibus") (Busa 1992) and was accompanied by a user guide in Latin, English, and Italian. Father Busa himself was the first recipient of the Busa award in recognition of outstanding achievements in the application of information technology to humanistic research, and in his award lecture in Debrecen, Hungary, in 1998 he reflected on the potential of the World Wide Web to deliver multimedia scholarly material accompanied by sophisticated analysis tools (Busa 1999). ${ }^{1}$ (HOCKEY, 2004, p.4)

A força dessa tradição de produção de saber associada com os avanços da computação fizeram com que outras pesquisas com o cunho de unir Humanidades com os Dígitos fossem executadas chegando, inclusive, ao solo baiano, no grupo de pesquisa da Universidade Federal da Bahia, capitaneado pelo professor Nilton Vasco da Gama e monitorado pela professora Célia Marques Telles.

\footnotetext{
${ }^{1}$ Um programa de concordância puramente mecânico, onde as palavras são alfabetizadas de acordo com suas formas gráficas (sequências de letras), poderia ter produzido um resultado em menor tempo, mas Busa não ficaria satisfeito com isso. Ele queria produzir uma concordância "lematizada" onde as palavras são listadas sob seus títulos de dicionário, não sob suas formas simples. Sua equipe tentou escrever algum software de computador para lidar com isso e, eventualmente, a lematização de todos os 11 milhões de palavras foi concluída de forma semiautomática com seres humanos lidando com formulários de palavras que o programa não poderia lidar. Busa estabeleceu padrões muito altos para seu trabalho. Seus volumes são elegantemente compostos e ele não comprometeria todos os níveis de erudição, a fim de obter o trabalho feito mais rápido. Ele continuou a ter uma profunda influência na computação de humanidades, com uma visão e imaginação que ultrapassam os horizontes de muitos da geração atual de profissionais que foram educados com a Internet. Um CD-ROM do material de Aquino apareceu em 1992 e incorporou algumas características hipertextuais ("cum hypertextibus") (Busa 1992) e foi acompanhado por um manual do usuário em latim, inglês e italiano. O próprio Padre Busa foi o primeiro a receber o prêmio Busa, em reconhecimento às conquistas notáveis na aplicação da tecnologia da informação à pesquisa humanística e em sua conferência de premiação, em Debrecen, na Hungria, em 1998, refletiu sobre o potencial da World Wide Web para oferecer Material acadêmico multimídia acompanhado de sofisticadas ferramentas de análise (Busa 1999).
} 
Foi lá que, em 2004, Alícia Duhá Lose, então orientanda de doutorado da professora Célia, teve contato com um pequeno manual do Estadão que ensinava a lidar com o Front Page, um software disponibilizado pelo pacote da programas da Microsoft para uso em computador doméstico e, usando tal material, deu origem à primeira edição digital desenvolvida em solo baiano, fazendo nascer uma tradição que, ano após ano, amplia-se vertiginosamente, dando origem a diversos trabalhos que serão aqui exemplificados e comentados, utilizando uma ficha de descrição de edição digital desenvolvida por Rafael Marques Ferreira Barbosa Magalhães e pela autora do artigo quando, em 2014, estavam coletando modelos de edições digitais para criação da Edição Digital dos Livros do Tombo do Mosteiro de São Bento da Babia, um projeto ainda em andamento. Ressalta-se que a exemplificação será feita com dois trabalhos dos dois grupos de pesquisa filológica vinculados à Universidade Federal da Bahia

\subsection{GRUPO DE PESQUISA DO MOSTEIRO DE SÃO BENTO DA BAHIA}

O Grupo de Pesquisa do Mosteiro de São Bento da Bahia atua no acervo da instituição, um acervo composto livros raros, livros de uso corrente e

[...] documentos manuscritos que datam desde o séc. XVI, entre eles se encontram: bulas papais, cartas de profissão dos monges, sermões, dietário com a história de todos os monges desde a fundação do Mosteiro, documentos relativos à vida privada do Mosteiro, documentos de Catarina Paraguaçu, cartas de alforria de escravos, documentos de compra e venda de escravos, documentação relativa às propriedades de toda a região metropolitana de Salvador, livros de pedidos de oração, entre diversos outros documentos, com os mais variados temas e estilos (ANDRADE; LOSE, 2007, p. 19).

O grupo atua sobre coordenação da professora doutora Alícia Duhá Lose e já desenvolveu cinco edições digitais. São elas: A edição digital do Livro I do Tombo, desenvolvida por Marla Oliveira Andrade; A edição digital dos Sermões de Frei Domingos da Transfiguração Machado, desenvolvida por Marília Andrade Nunes; As edições do Livro de Aforamentos e do Livro de Crônicas do do Mosteiro de São Bento da Bahia, desenvolvidas por Lívia Borges Souza Magalhães. Além disso há a edição dos rascunhos de Arthur de Salles, de responsabilidade da coordenadora do grupo, mas não feita com documentação da abadia.

\subsubsection{Ficha para estudo de edição digital 1}

\begin{tabular}{|l|l|}
\hline \multicolumn{1}{|c|}{ Título } & $\begin{array}{l}\text { Edição digital das pastas 001 e 003 do Acervo de Arthur de } \\
\text { Salles }\end{array}$ \\
\hline Responsável pela criação & Alícia Duhá Lose \\
\hline Responsável pela execução & Alícia Duhá Lose \\
\hline Ano & 2004 \\
\hline $\begin{array}{l}\text { Programa para } \\
\text { desenvolvimento }\end{array}$ & Front page \\
\hline Instituição de vinculação & Universidade Federal da Bahia \\
\hline Formato & (X) Website / ( ) E-book / ( ) Outro \\
\hline Disponível on-line & ( ) Sim ( X ) Não \\
\hline Mídias incorporadas & $\begin{array}{l}\text { (X) Imagem / (X) Som / ( ) Imagem em movimento / } \\
\text { () Outro }\end{array}$ \\
\hline Referência & $\begin{array}{l}\text { LOSE, Alícia Duhá. Arthur de Salles: esboços e rascunhos. } \\
\text { 2004. 265f. il. + anexos + 1 CD-ROM (edição digital). Tese }\end{array}$ \\
\hline
\end{tabular}




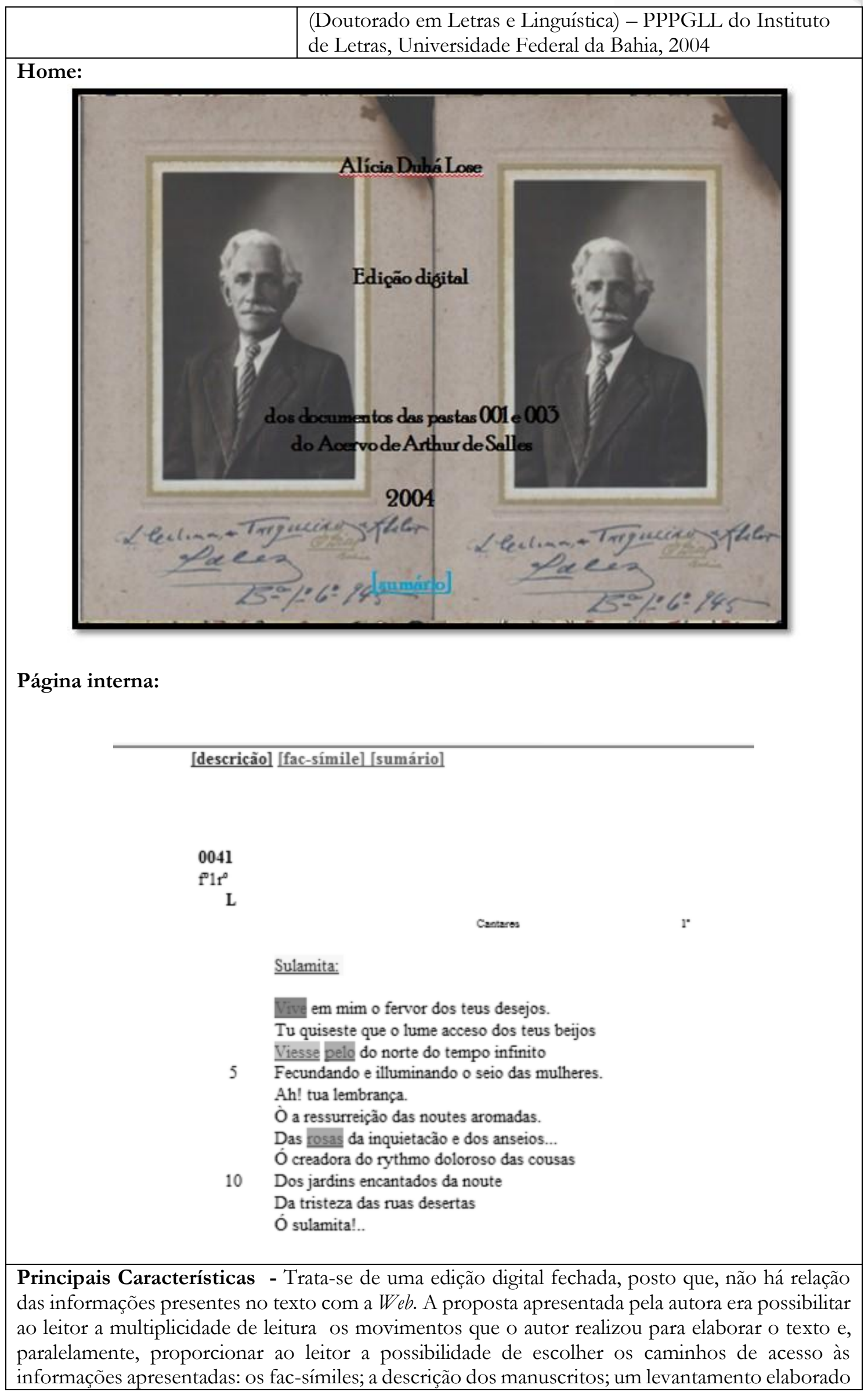


do vocabulário, da estrutura poética e das temáticas de uso do poeta; a biografia do autor; a obra mais divulgada dele: o Hino ao Senhor do Bonfim; e, por fim, uma lista de todos trabalhos executados pelo grupo de pesquisa da UFBA com o acervo do poeta.

\subsubsection{Ficha para estudo de edição digital 2}

\begin{tabular}{|c|c|}
\hline Título & $\begin{array}{l}\text { Edição digital do Livro de Crônicas Mosteiro de São } \\
\text { Bento da Bahia }\end{array}$ \\
\hline Responsável pela criação & Lívia Borges Souza Magalhães \\
\hline $\begin{array}{l}\text { Responsável pela } \\
\text { execução }\end{array}$ & Lívia Borges Souza Magalhães \\
\hline Ano & 2013 \\
\hline $\begin{array}{l}\text { Programa para } \\
\text { desenvolvimento }\end{array}$ & Front Page e NVU \\
\hline Instituição de vinculação & Universidade Federal da Bahia \\
\hline Formato & (X) Website / ( ) Ebook / ( ) Outro \\
\hline Disponível on-line & ( ) $\operatorname{Sim}(\mathrm{X})$ Não \\
\hline Mídias incorporadas & $\begin{array}{l}\text { (X) Imagem / (X) Som / ( ) Imagem em movimento / } \\
\text { ( ) Outro }\end{array}$ \\
\hline Referência & $\begin{array}{l}\text { MAGALHÃES, Lívia Borges Souza. Fazendo filologia } \\
\text { entre tags e dígitos binários: uma proposta de edição } \\
\text { digital do Livro de Crônicas do Mosteiro de São Bento da } \\
\text { Bahia. 2013. } 418 \text { f. }+1 \text { pen drive (edição digital). } \\
\text { Dissertação (Mestrado em Letras e Linguística)-- } \\
\text { Instituto de Letras, Universidade Federal da Bahia, } \\
\text { Salvador, 2013. }\end{array}$ \\
\hline
\end{tabular}

Home:

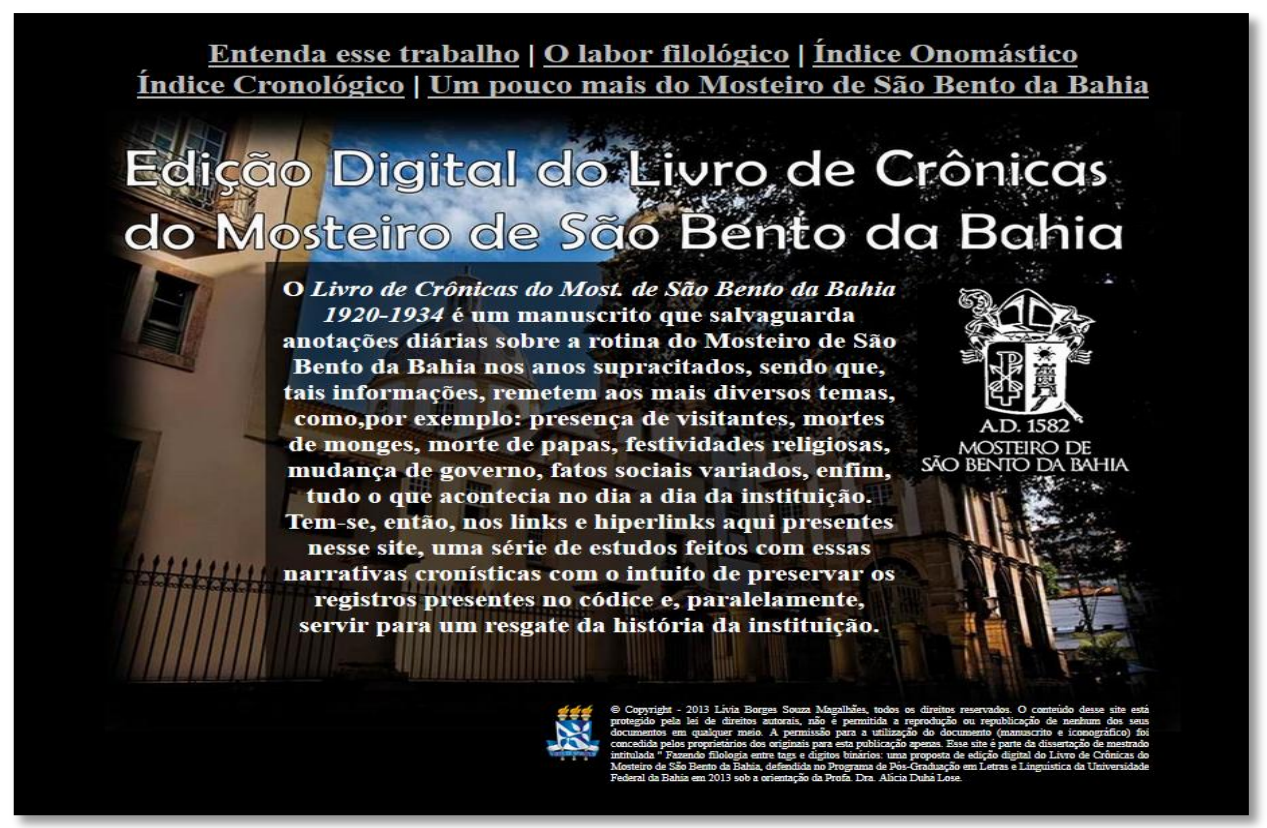




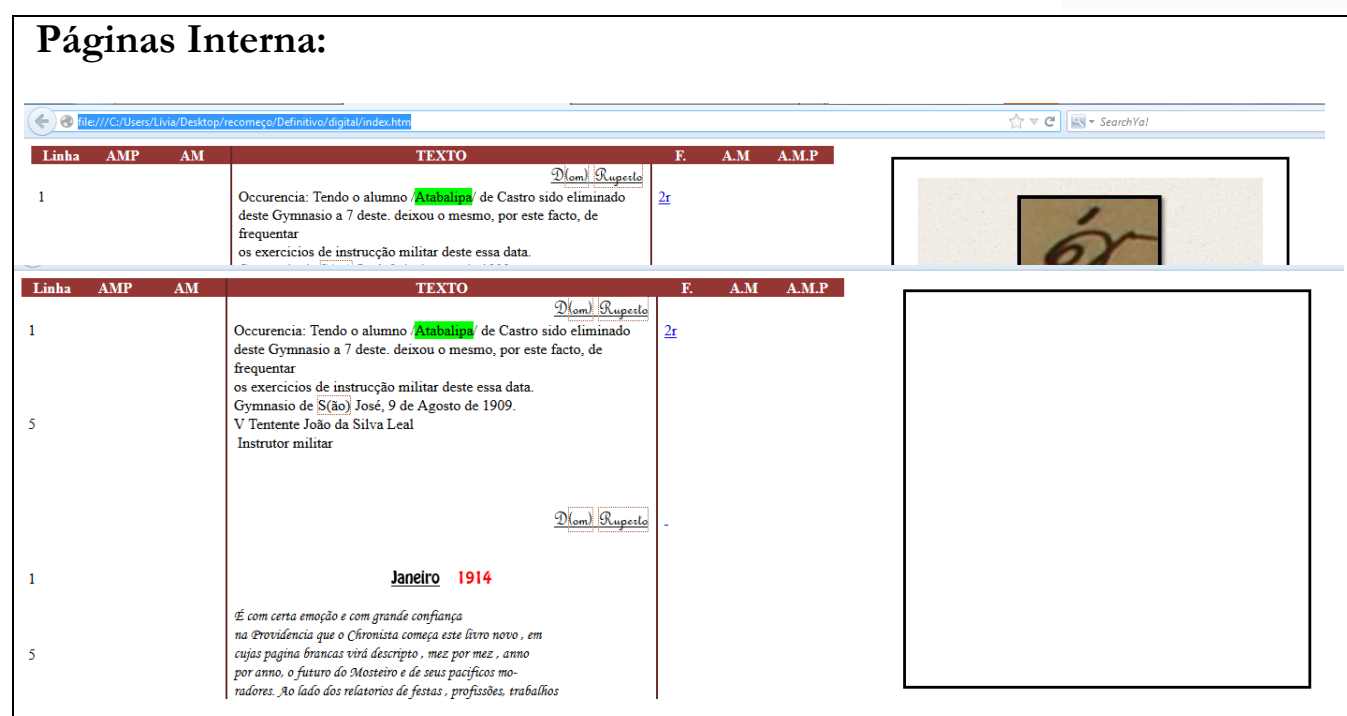

Principais Características - É uma edição de navegação aberta, com diversos links unindo os registros históricos presentes no manuscrito com os registros historiográficos já encontrados na web. A proposta da edição era, primordialmente, permitir ao leitor da edição o acesso à multiplicidade de abreviaturas presentes no texto, mas, inseriu-se, também, imagens capazes de ilustrar o arcabouço cultural do manuscrito. $\mathrm{O}$ trabalho foi feito através da inserção de uma código java na head do site para, então, ordenar que, no body, quando o mouse passe por cima de uma informação "linkada", ela apareça (primeira imagem da página interna), e quando o mouse saia de cima, ela suma (segunda imagem da página interna).

\subsection{EQUIPE TEXTOS TEATRAIS CENSURADOS}

Coordenado pela professora Doutora Rosa Borges dos Santos, a equipe é parte do Grupo de Edição e Estudo de Textos (GEET) e atua em acervos como o do espaço Xisto Bahia ou do Teatro Vila Velha, que salvaguardam textos de dramaturgos baianos que foram censurados durante o período da Ditadura Militar. A equipe desenvolve, tradicionalmente, edições críticas e interpretativas, mas, desde de 2011, passou a utilizar a tecnologia para desenvolvimento de edições e, desde então, contabilizou a produção de sete edições: $O$ desabrochar de uma flor em tempos de repressão: edição e crítica filológica de Apareceu a Margarida de Roberto Athayde e Três fios do bordado de Jurema Penna: leituras filológicas de uma dramaturgia baiana, ambas desenvolvidas por Isabela Almeida; Aprender a nada-r e Anatomia das feras, por Débora de Souza; Malandragem made in Babia, por Williane Silva Corôa; Irani ou As Interrogações, por Mabel Meire Mota; O desabrochar de uma flor em tempos de repressão: edição e crítica filológica de Apareceu a Margarida de Roberto Athayde, por Fabiana Prudente Correia; Arquivo Hipertextual de Greta Garbo, quem diria, foi parar no Irajá, por Arivaldo Sacramento de Souza.

\subsubsection{Ficha para estudo de edição digital 3}

\begin{tabular}{|l|l|}
\hline Título & Auto da Barca do Rio das Lágrimas de Irati \\
\hline Responsável pela criação & Isabela Santos de Almeida \\
\hline $\begin{array}{l}\text { Responsável pela } \\
\text { execução }\end{array}$ & Isabela Santos de Almeida e Alan Nunes \\
\hline
\end{tabular}




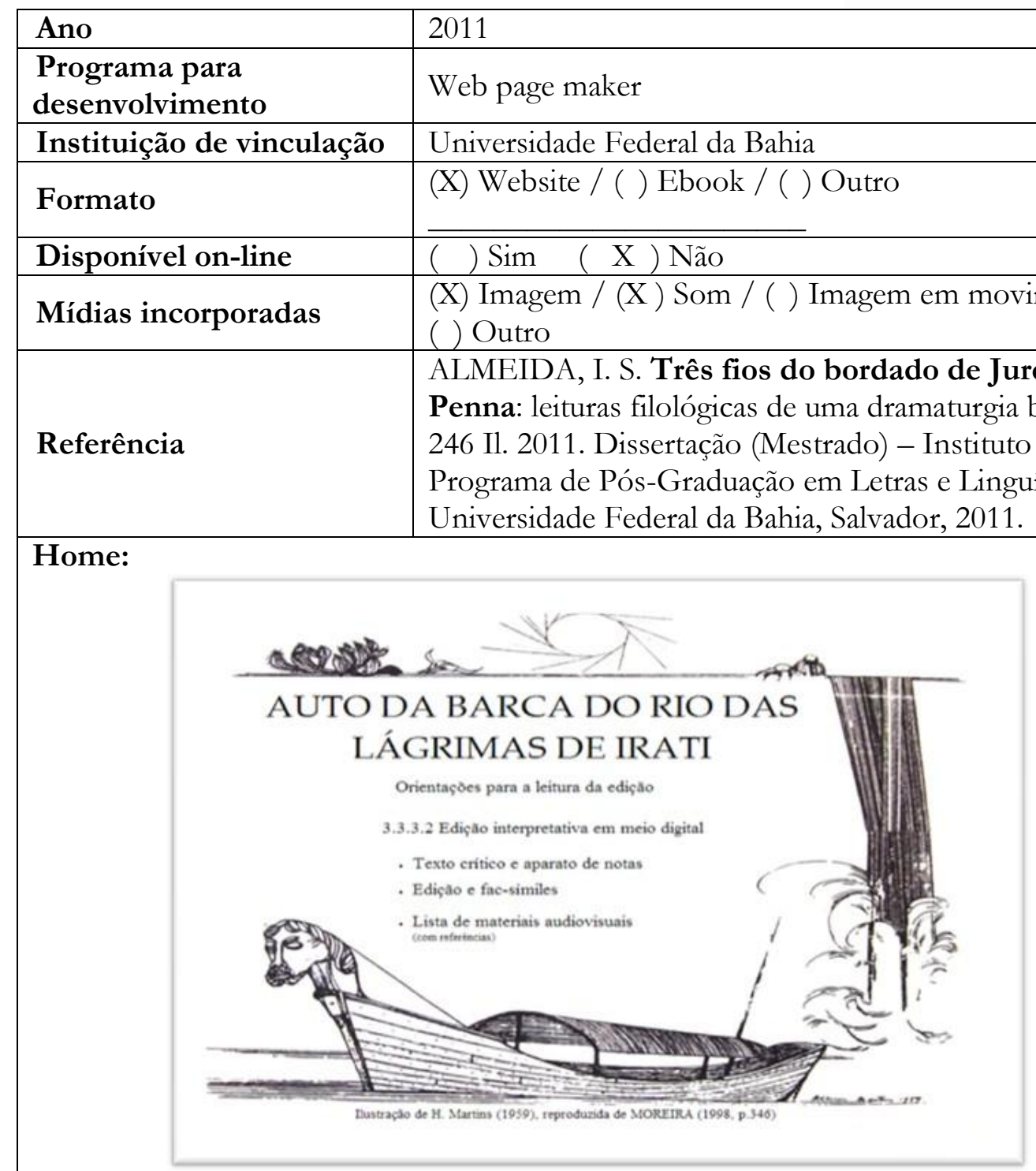

\section{Página Interna:}

PROJETO CHAPÉU DE PALHA

Juazeiro-Ba. - Novembro/Dezembro - 1983

Roteiro de Jurema Penna

Neste texto foram usados poemas de:

Pedro Raimundo, Antonio de Santana Padilha, Manuka, Josias, Wilson G. Duarte, Dedé, Esmelinda Pergentino Nunes, Euvaldo Macedo Fitho, Ruy Santos, Joseph Wallacortanta Bandeira, João Gilberto, Paulo Benevides, G. Muccini e Otoniel Gondim.

Músicas: Beethoven, Brahms, Chopin, Vivaldi, Orquestra Armorial, Carlos Pita, Mauriçola e Folclore Regional. 
Principais Características - Edição digital aberta em que se apresenta uma edição interpretativa, com links para o aparato das variantes através do uso de caixas flutuantes e links direcionando para páginas da web

\subsubsection{Ficha para estudo de edição digital 4}

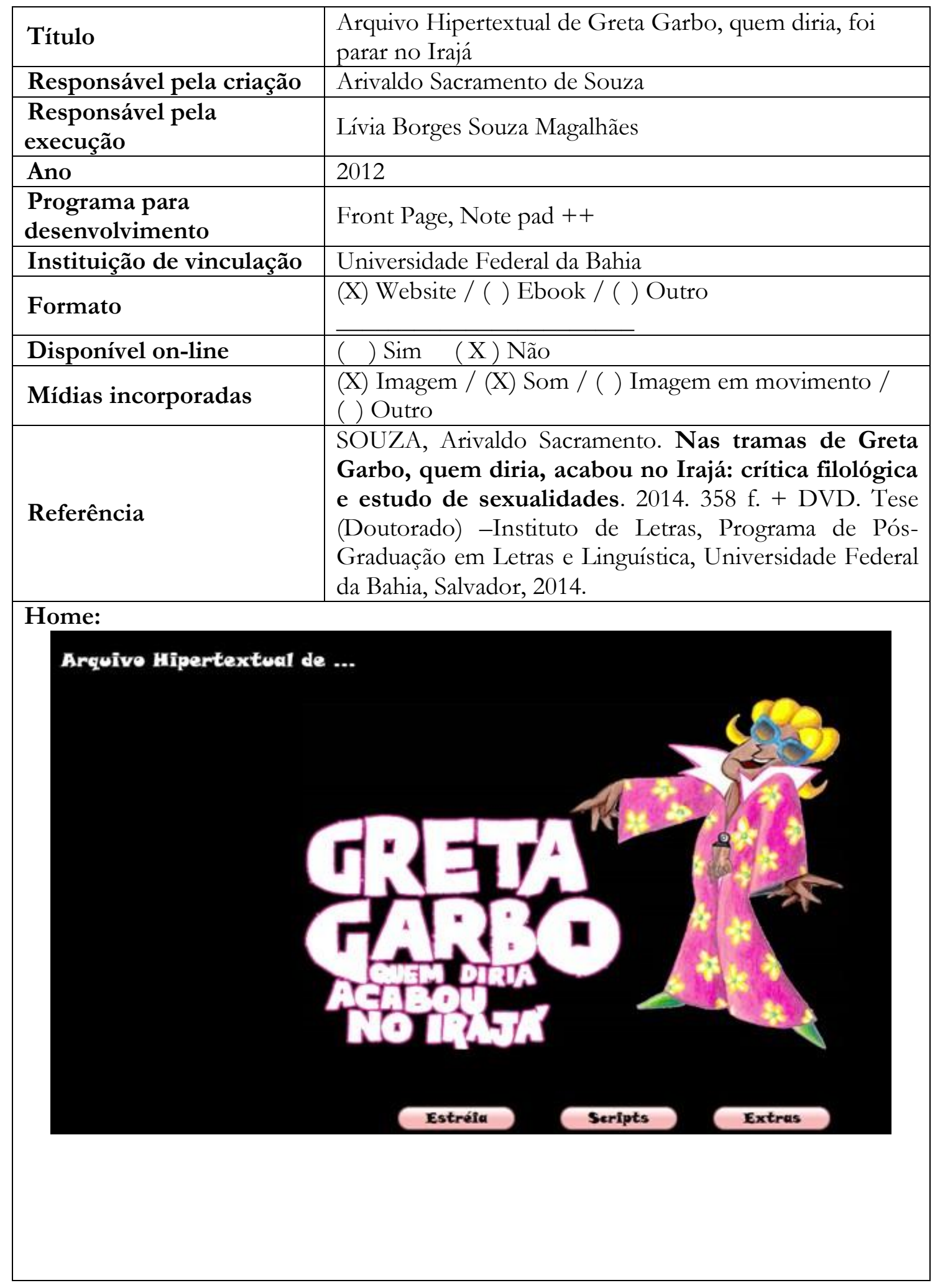




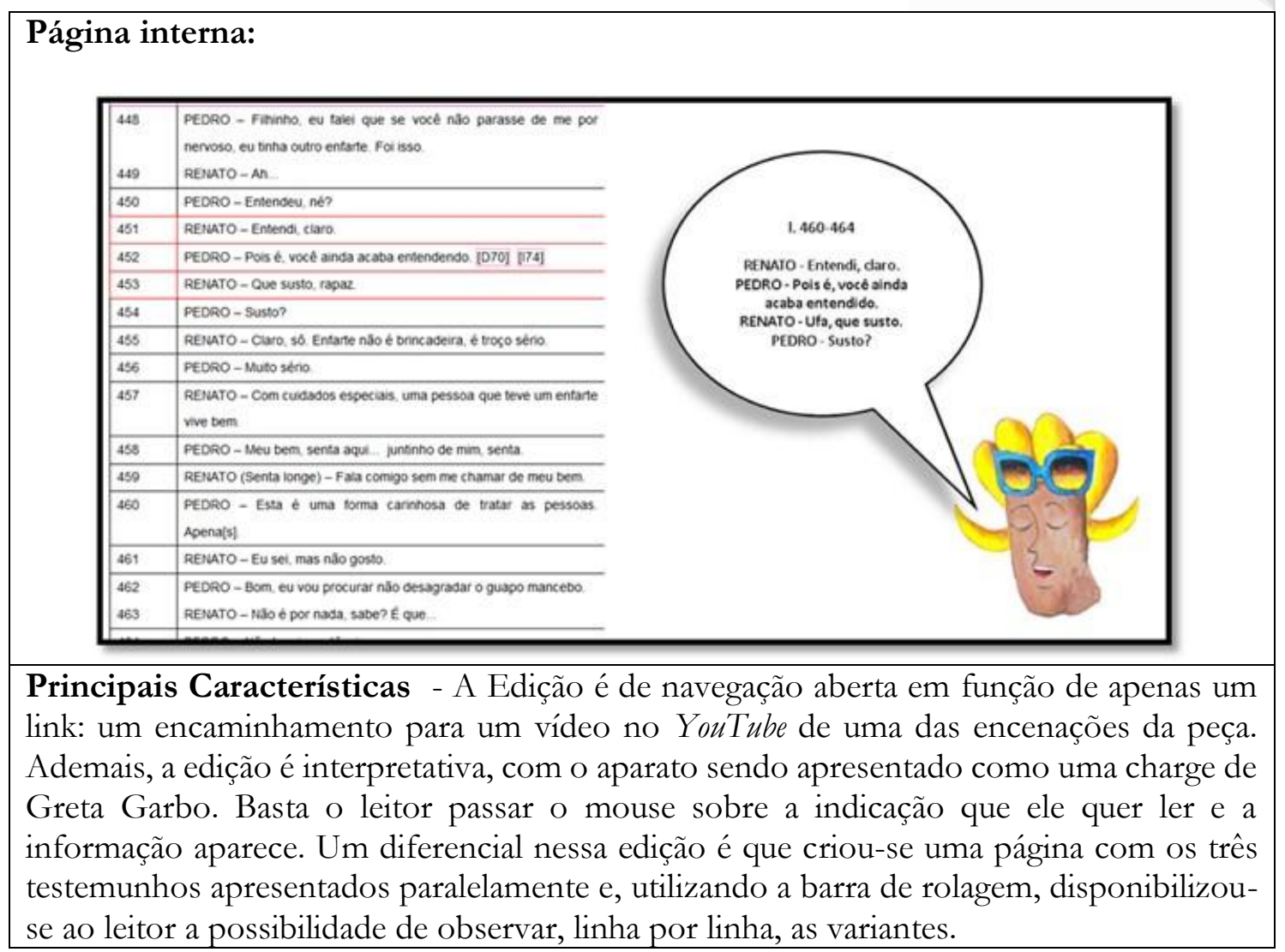

\section{CONSIDERAÇÕES FINAIS}

As fichas de descrição de edição digital aqui apresentadas são uma pequena parte de um levantamento de todas as edições digitais filológicas desenvolvidas na Bahia, um trabalho realizado com o intuito de observar o movimento de inserção das práticas tecnológicas computacionais na filologia baiana e construir um registro de cunho histórico e memorialístico de tais edições, já que, quando trata-se de tecnologia, as mudanças são constantes e necessárias para seguir o fluxo de atualização tecnológica.

Assim, destaca-se que o filólogo pode (e precisa) debruçar-se sobre as diversas áreas do saber para buscar compreender o objeto de estudo que tem em mãos. Em outras palavras, ele deve buscar conhecimentos relativamente consideráveis sobre o texto que está analisando e, sabendo que o texto é um produto social, cultural e histórico, torna-se impossível não pensar em uma relação direta entre a filologia e as ciências da computação, para a criação de edições transdisciplinares, mais completas, abertas e capazes de inserir a Filologia no rol das Humanidades Digitais.

\section{REFERÊNCIAS}

ALMEIDA, Isabela. Santos de. Três fios do bordado de Jurema Penna: leituras filológicas de uma dramaturgia baiana. f. 246 Il. 2011. Dissertação (Mestrado) - Instituto de Letras, Programa de Pós-Graduação em Letras e Linguística, Universidade Federal da Bahia, Salvador, 2011.

ANDRADE, Marla Oliveira; LOSE, Alícia Duhá. Pesquisas filológicas nos acervos da Biblioteca Histórica do Mosteiro de São Bento da Bahia. Scripta Philologica. Salvador, n. 3, 2007. CD-ROM. 
CHARTIER, Roger. A aventura do livro: do leitor ao navegador: conversações com Jean Lebrun. Tradução Reginaldo Carmello Corrêa de Moraes. São Paulo: Imprensa Oficial do Estado de São Paulo; Editora UNESP, 2009.

HOCKEY, Susan. The History of Humanities Computing. In: SCHREIBMAN, Susan; SIEMENS, Ray; UNSWORTH, John. (Orgs.). A Companion to Digital Humanities. . Disponível em:

http:/ /www.digitalhumanities.org/companion/view?docId=blackwell/9781405103213/97 81405103213.xml\&chunk.id=ss1-1-3\&toc.depth=1\&toc.id=ss1-1-3\&brand=default.

Acesso em: 15 jul. 2016.

LEÃO, Lucia. O labirinto da hipermídia: arquitetura e navegação no ciberespaço. São Paulo: Iluminuras, 1999.

LOSE, Alícia Duhá et al. Edições digitais de manuscritos: do século XVI ao século XXI. In: CIRILLO, José; PASSOS, Marie- Hélène Paret (Org.). Materialidade e virtualidade no processo criativo. Vinhedo, SP: Horizonte, 2011. p. 77-99.

LOSE, Alícia Duhá. Arthur de Salles: esboços e rascunhos. 2004. 265f. il. + anexos + 1 CDROM (edição digital). Tese (Doutorado em Letras e Linguística) - PPPGLL do Instituto de Letras, Universidade Federal da Bahia. Orient.: Profa. Dra. Célia Marques Telles, 2004.

MAGALHÃES, Lívia Borges Souza. Fazendo filologia entre tags e dígitos binários: uma proposta de edição digital do Livro de Crônicas do Mosteiro de São Bento da Bahia. 2013. 418 f. + 1 pen drive (edição digital). Dissertação (Mestrado em Letras e Linguística) - Instituto de Letras, Universidade Federal da Bahia, Salvador, 2013.

RIBEIRO, Ana Elisa. Os hipertextos que Cristo Leu. In. ARAÚJO, Júlio Cesar; BIASIRODRIGUES, Bernadete. Interação na Internet: novas formas de usar a linguagem. Rio e Janeiro: Lucerna, 2005.

RIFKIN, Jeremy. A terceira A Terceira Revolução Industrial: como a nova era da informação mudou a energia, a economia e o mundo. Lisboa: Bertrand, 2014.

SERRA, Liliana Giusti. Livro digital e bibliotecas. Rio de Janeiro: FGV, 2014.

SOUZA, Arivaldo Sacramento. Nas tramas de Greta Garbo, quem diria, acabou no Irajá: crítica filológica e estudo de sexualidades. 2014. 358 f. + DVD. Tese (Doutorado) -Instituto de Letras, Programa de Pós-Graduação em Letras e Linguística, Universidade Federal da Bahia, Salvador, 2014.

WOOD JR., T. Caos: A criação de uma nova ciência? As aplicações e implicações da Teoria do Caos na Administração de Empresas. Revista Administração Empresas, v. 33, n.4, p. 94-105, 1993. 